\title{
Modified AFLP Technique for Rapid Genetic Characterization in Plants
}

BioTechniques 29:858-866(October 2000)

\author{
Daya G. Ranamukhaarachchi, \\ Michael E. Kane, Charles L. \\ Guy and Qin B. Li \\ University of Florida, \\ Gainesville, FL, USA
}

\section{INTRODUCTION}

Molecular markers provide a useful tool to obtain a considerable fraction of the genetic information available within an organism $(2,10)$. The selection of a molecular technique to generate markers depends on the specific objective, analytical power (resolution between samples), knowledge requirement, time, cost and reliability. Restriction fragment-length polymorphism (RFLP) markers generate accurate data and produce allelic information on different loci. However, resolution is low in terms of the polymorphism generated, and the applicability of RFLP is restricted due to the use of radioisotopes, the need for large quantities of DNA and prior sequencing knowledge required to synthesize single-locus and multi-locus probes. With extensive allelic information, variable number of tandem repeats (VNTR) (also termed microsatellites and minisatellites) generate the maximum resolution between individuals. Microsatellites provide ideal codominant markers for genetic characterization because multiple allelic information at a single-locus level is generated with a high degree of reproducibility $(1,2,12)$. However, generating microsatellite markers is constrained by the practical difficulties mentioned for RFLP as well as difficulty in generating microsatellite libraries.

A number of techniques have evolved with the advent of PCR technology such as random amplified polymorphic DNA (RAPD) (25), arbitrarily primed-PCR (AP-PCR) (24) and DNA amplification fingerprints (DAF) (3). These methods generate more markers than RFLP. Because of the large num ber of primer combinations that can be generated, PCR-based techniques theoretically provide an endless source of priming sites for thorough multi-loci screening of any organism.

Techniques that use arbitrary primers are less expensive, rapid, do not require radioisotopes and can be used to obtain genetic information on genetically unknown organisms. However, owing to low annealing temperature conditions, these techniques often generate artifactual bands associated with misannealing of primers and result in poor reproducibility of the markers. Intensity of the bands between individuals could be different, causing ambiguity in scoring (10), especially when a large number of samples are used for the experiment. This has necessitated repeating the same experiment until a consistent banding pattern is obtained. This problem creates frustration because of the waste of time and resources.

The more recently developed amplified fragment-length polymorphism (AFLP) technique (22) uses both principles of RFLP and techniques such as RAPDs. It generates an extensive level of polymorphism between individuals with high reproducibility and uniform intensity of bands. However, the AFLP technique also requires radioisotopes, extensive laboratory skills and is time consuming. These limitations restrict using techniques such as AFLP to only more sophisticated laboratories (23). Progress in developing new techniques is needed in two directions, simplicity and analytical power (7). Thus, an ideal technique would be one with the ease of RAPD while retaining the power of reproducibility and uniform intensity of bands generated between samples.

The standard AFLP technique consists of $(i)$ restriction-digestion of genomic DNA using two restriction enzymes (a rare cutter and a frequent cutter) in separate steps; (ii) ligation of synthetically generated adapters with 
DNA sequences corresponding to the sticky ends of restricted DNA products; (iii) preselective PCR amplification using two primers complementary to the adapter-ligated ends with one preselected base at the $3^{\prime}$ end; and (iv) selective amplification generating the final products by a second series of radiolabeled primers that generally contain three tandemly oriented preselected bases at the $3^{\prime}$ end. These amplified products are then separated by PAGE on a DNA sequencing gel apparatus (22). Handling and disposal of radioisotopes and making sequencing gels require extreme care.

In this paper, we describe a modified AFLP protocol that was developed for rapid genetic characterization of plants. Major modifications to the standard AFLP technique involved $(i)$ using only one restriction enzyme, one adapter and one primer, (ii) agarose gel electrophoresis to separate bands followed by ethidium bromide staining and (iii) incorporating formamide to generate more intense and uniform bands. This modified method involves considerably fewer steps compared to the standard AFLP technique (22) while maintaining high reproducibility with analytical power equal to or greater than RAPD. Different modifications to AFLP have been reported for genetic characterization of fungi (13) and honeybees (21). Plants contain higher quantities of phenolic compounds and polysaccharides that may prevent complete digestion of DNA, which is an important step in the AFLP technique. We have tested AFLP modifications for several plant species to determine ( $i$ ) simplicity, reproducibility, equal intensity and analytical power, and (ii) the ability to serve as a reliable molecular tool to generate markers in plants for a wide range of applications.

\section{MATERIALS AND METHODS}

\section{Plant Materials}

For the study, we selected four plant species: sea-oats (Uniola paniculata L.), pickerel-weed (Pontederia cordata L.), Bermudagrass (Cynodon dactylon L.) and Penstemon heterophyllus Lindl. Sea-oats is a subtropical coastal dune grass, while pickerel-weed is naturally found in wetland conditions. Bermudagrass is horticulturally important for turf management. $P$. heterophyllus is a self-pollinated, terrestrial, herbaceous plant. These species were selected to test the performance of AFLP modifications on generating polymorphism for different plant species. Ecotypic samples of pickerel-weed from Rhode Island to South Florida, different cultivar samples of Bermudagrass (FHB-88, FHB-89, Floratex [BS.FB-119], FHB285, FHB-319, Tifdwarf, Tifgreen and FHB-281) grown in the eastern United States, samples from a disjunct population of Penstemon and Florida population samples of sea-oats, were collected. DNA was extracted using a modified method of Murray and Thompson (14), which uses cetyltrimethylammonium bromide (CTAB) extraction buffer. Modifications included $(i)$ replacing octanol by isoamyl alcohol and (ii) precipitation of DNA using 100\% ethanol.

\section{Restriction Digestion and Ligation}

Three restriction enzymes, EcoRI, TaqI, and MseI, were used to prepare template DNA by single enzyme digestions. Adapters for ligation reactions were prepared as reported by Janssen et al. (9). The protocol for preparing template DNA is given here using EcoRI and is common to all the restriction enzymes. Genomic DNA $(0.5 \mu \mathrm{g})$ was digested using $10 \mathrm{U}$ EcoRI enzyme. At this stage, experiments were conducted to evaluate the quality of the final products as influenced by restriction digestion/ligation in one reaction, and restriction digestion followed by ligation reaction in two steps. The latter was implemented based on the quality and the number of bands amplified. A total volume of $20 \mu \mathrm{L}$ digestion mixture consisted of EcoRI $(2 \mu \mathrm{L}), 10 \times$ reaction buffer $(2 \mu \mathrm{L})$ and a specific volume of genom ic DNA solution that contained approximately $0.5 \mu \mathrm{g}$ DNA. The digestion mixture was incubated at $37^{\circ} \mathrm{C}$ for $6 \mathrm{~h}$, followed by the addition of DNA ligase $(2 \mu \mathrm{L}), 5 \times$ reaction buffer $(2 \mu \mathrm{L})$ and 50 pmol EcoRI adapter $(1 \mu \mathrm{L})$ to the same digestion mixture, making a total volume of $25 \mu \mathrm{L}$. This mixture was incubated overnight (12-14 h) at room temperature. Following digestion/ligation, template DNA was purified from excess adapters, enzymes and other contaminants using $95 \%$ ethanol precipitation.

\section{PCR Amplification and Gel Electrophoresis}

In a series of preliminary experiments, PCR amplification conditions were optimized for $\mathrm{Mg}$, Taq DNA polymerase and template DNA concentrations. In another series of experiments using the above optimized conditions, effect of dimethyl sulfoxide (DMSO), formamide and bovine serum albumin (BSA) were also tested for improving DNA profiles. Based on these results, the final optimized amplification reaction conditions included $15 \mathrm{ng}$ template DNA, 2.5 U Taq DNA polymerase, 40 pmol primer, $200 \mu \mathrm{M}$ dNTPs, $2.5 \mathrm{mM}$ $\mathrm{MgCl}_{2}, 2 \%$ formamide, $1 \%$ BSA, 10 $\mathrm{mM}$ Tris- $\mathrm{HCl}, \mathrm{pH} 8.5,50 \mathrm{mM} \mathrm{KCl}$, all in a total volume of $15 \mu \mathrm{L}$. The optimized thermal cycling conditions were $2 \mathrm{~min}$ at $94^{\circ} \mathrm{C}$, followed by 40 cycles of $94^{\circ} \mathrm{C}$ for $25 \mathrm{~s}, 56^{\circ} \mathrm{C}$ for $25 \mathrm{~s}, 72^{\circ} \mathrm{C}$ for 25 $\mathrm{s}$ and a final extension at $72^{\circ} \mathrm{C}$ for $7 \mathrm{~min}$. Primers were synthesized as described in Vos et al. (22). Each primer consisted of DNA sequences complementary to a major part of the adapter sequences containing a specific restriction site plus arbitrarily assigned bases to the $3^{\prime}$ end of the primer. Two sets of primers were designed based on the number of arbitrary nucleotides used: two bases (18-mers) and three bases (19-mers).

PCR products were electrophoresed using a Synergel ${ }^{\mathrm{TM}}$ (Diversified BioTech, Boston, MA, USA) (16) and agarose $(1.73 \mathrm{~g}: 1.05 \mathrm{~g})$ gel mixture in $150 \mathrm{~mL} 0.5 \times$ TPE buffer (45 mM Trisphosphate and $1 \mathrm{mM}$ EDTA, pH 8.4) that would generate a similar strength to $3 \%$ standard agarose gel. Each lane consisted of $8 \mu \mathrm{L}$ PCR products, and the gels were run at $65 \mathrm{~V}$ for $8-10 \mathrm{~h}$. Bands were visualized by ethidium bromide staining (19).

\section{Specific Performance and Reliability Tests}

A number of experiments were conducted using EcoRI to test the performance and reliability of the modified AFLP technique. These tests were $(i)$ performance of amplified products using two sets of primers with two and 


\section{Research Report}

three degenerate bases at the $3^{\prime}$ end; (ii) reproducibility of the final products, between two different restriction digestions and between PCR amplifications at different time periods (one, two and four weeks); (iii) the ability to generate adequate resolution power for a wide range of plant species that included cultivars, ecotypes, individuals within and between populations and both self- and cross-pollinated plants; and (iv) comparison of RAPD and modified AFLP methods for generating polymorphism for population studies.

\section{RESULTS AND DISCUSSION}

\section{AFLP Modifications and Optimizing Experimental Conditions}

Of the three restriction enzymes tested, based on the type of primer (18mer or 19-mer) used, EcoRI and MseI generated amplified bands that could be separated by Synergel:agarose gel electrophoresis. Both enzymes generated more than 10 clearly visible bands when 19-mer primers having three selective bases were used, while 18-mer primers with two selective bases caused a smear on each lane of the gel. The observed differences in primers resulted from the reduction in selection of complementary DNA strands from 1/64 possibilities ( 1 in $4 \times 4 \times 4$ nucleotides) in 19 -mers to $1 / 16$ ( 1 in $4 \times 4$ nucleotides) in 18 -mer primers. Thus, when 18-mer primers are used, too many bands may be generated, resulting in a smear. If 18-mer primers are used for amplification, it may be necessary to increase the resolution power of gels either by increasing Synergel: agarose concentration or by using polyacrylamide gels for better separation of the bands. TaqI enzyme always produced bands with a smear in both cases.

Restriction digestion followed by ligation in two separate steps produced better results compared to digestion and ligation in one reaction. This is in contrast to the AFLP modifications reported earlier for other eukaryotic systems except plants $(13,21)$. In general, plants contain higher quantities of polyphenolic compounds and polysaccharides that are often co-precipitated with DNA $(6,18)$. Both may lead to partial or poor digestion of DNA (10, 11 ), which is an important step in the AFLP technique. However, not com bining the digestion/ligation into one step did not affect the rapidity and efficiency of the technique because, after the digestion, we added the ligation mixture to the digestion solution (see Materials and Methods), which was not a difficult step.

Addition of $2 \%$ formamide alone or with $0.5 \%$ BSA improved DNA amplifications and band intensity. DMSO at $5 \%$ or $10 \%$ concentrations always resulted in no amplification. Specificity of bands was greatly enhanced at the $2 \%$ level compared to no formamide, which allowed better band scoring. However, template DNA concentrations less than $10 \mathrm{ng} / 15 \mu \mathrm{L}$ PCR mixture resulted in inhibition of amplification by formamide. Formamide weakens the hydrogen bonding between nucleotides and helps in destablizing DNA in solution $(4,27)$. Organic solvents also prevent primer secondary structure formation (17). This property facilitates the primer annealing step and improves PCR in DNA sequencing and amplification, especially in DNA regions with high GC content $(17,20,26,27)$. Therefore, adding formamide is a simple step

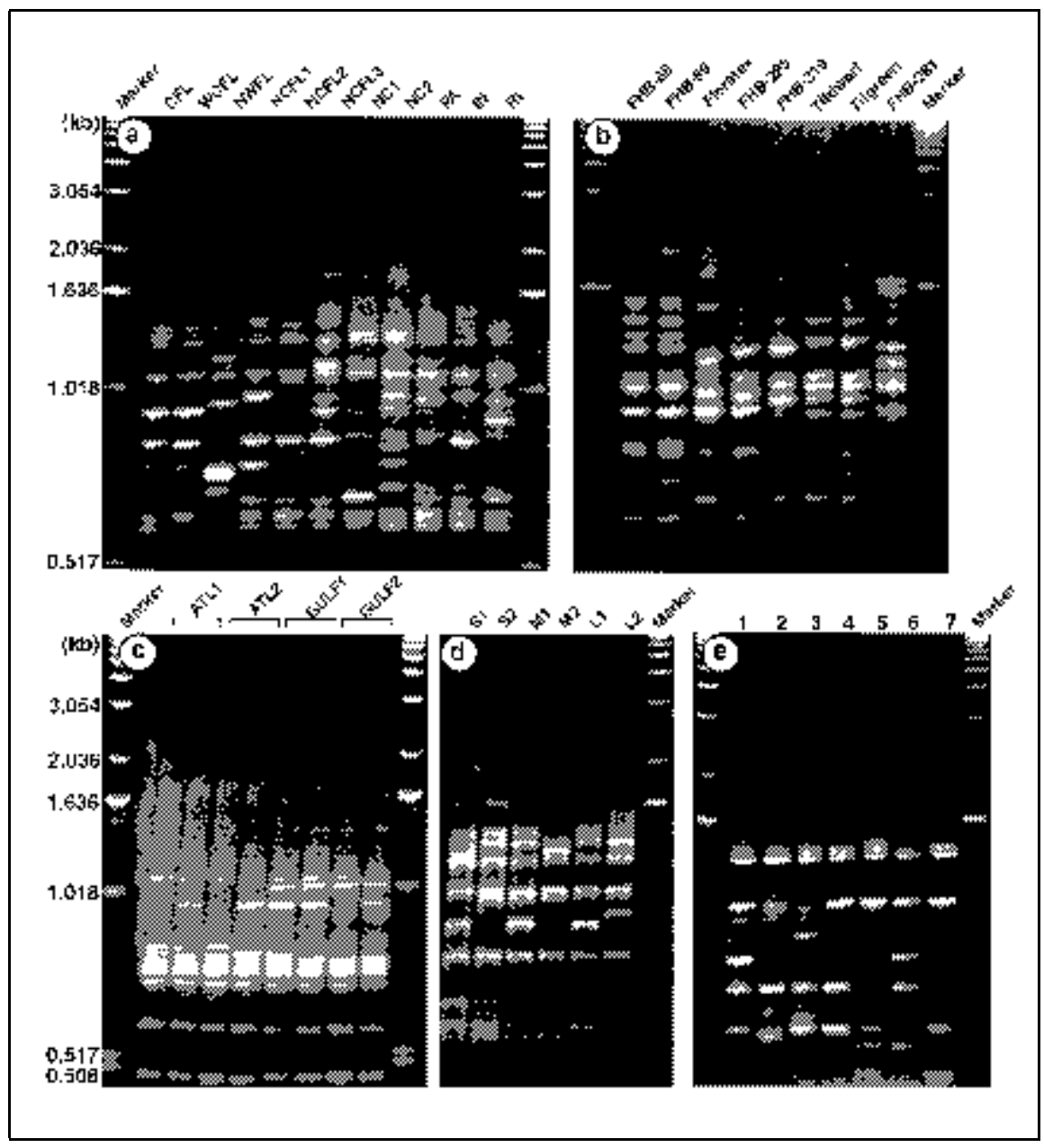

Figure 1. Polymorphism generated using a modified AFLP technique with four plant species. (a) Ecotypic samples of pickerel-weed (P. cordata L.) (each lane represents one ecotype) collected in natural populations from Rhode Island to South Florida. (b) Turfgrass cultivars of Bermuda grass $(C$. dactylon) grown in the United States. (c) Individual sea-oats (U. paniculata) samples collected from two Gulf and two Atlantic coast populations in Florida. (d) Individual pickerel-weed samples collected from a single disjunct population in Gainesville, FL, USA to show within population variation. (e) Individual $P$. heterophyllus samples collected from a single disjunct population in Gainesville, FL, USA. Note that the modified AFLP procedure generated polymorphism in each species that can be used to identify individuals (within and between populations), cultivars and ecotypic samples. 
that is useful in generating AFLP with improved intensity of bands.

\section{Generating Polymorphism among Plant Samples}

We screened eight AFLP primers (19-mers) that generated extensive polymorphism for all the species tested including ecotypic samples (Figure 1a), cultivars (Figure 1b) and individual samples within natural populations (Figure 1, c, d and e). Of the plant samples tested, ecotypic samples of pickerel-weed and turfgrass cultivars (Guy and $\mathrm{Li}$, unpublished data) have been previously tested using the RAPD method. However, both required extensive random primer screening to generate adequate polymorphism to allow separation of samples. For pickerel- weed and turfgrass cultivars, 40 and 60 random primers were screened, respectively. However, even after screening 60 RAPD primers, it was not possible to differentiate some turfgrass cultivars (e.g., cultivar samples FHB-319, Tifdwarf and Tifgreen). Using our modified AFLP technique, we were able to differentiate some of the cultivars that could not be differentiated by RAPD (e.g., FHB-319 vs. Tifdwarf or Tifgreen) (Figure 1b). However, we tested only four 19-mer primers in this case, and, if more primers are used, there is a potential for further differentiating closely related individuals such as Tifdwarf and Tifgreen. This is a timesaving and important application of our modified AFLP technique over RAPD.

Among experiments conducted to determine the ability to differentiate

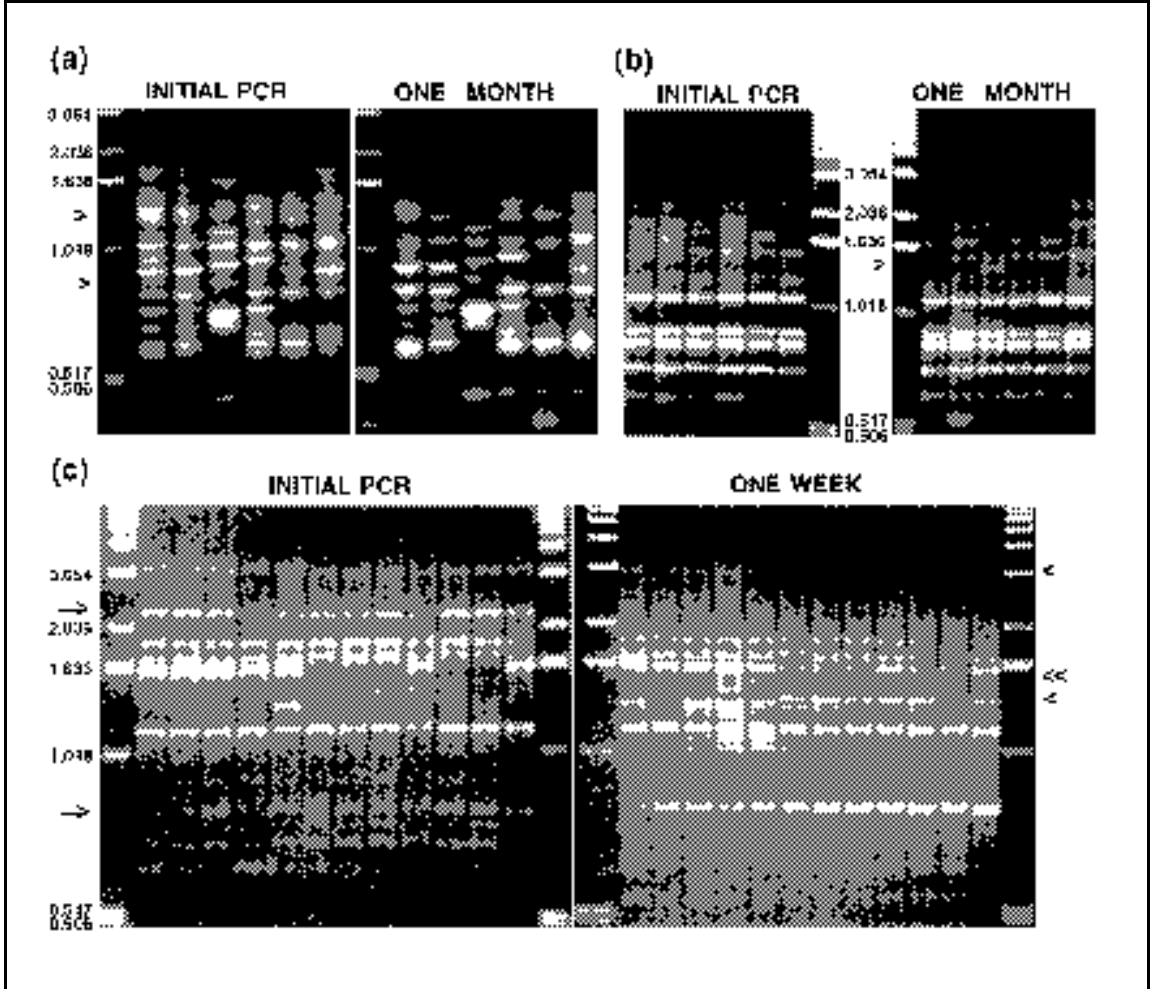

Figure 2. Reproducibility of amplified bands with the modified AFLP technique and RAPD. Reproducibility of modified AFLP was tested at two different levels. (a) Reproducibility between PCR tests conducted at different time intervals for the same restriction digested/ligated template DNA samples. (b) Reproducibility between PCR tests conducted for the same template DNA samples obtained by two different restriction digestion/ligation reactions. (c) Reproducibility between PCR tests conducted at different time intervals for the RAPD-PCR. Results using genomic DNA samples were from sea-oats (U. paniculata L.) are shown. Reproducibility for all plant species examined was very high using the modified AFLP technique (data not shown). > indicates the bands missing between PCR tests over a period of four weeks and two restriction digestion/ligations. Arrows indicate bands missing between two RAPD-PCR. $<<$ indicates a polymorphic band in initial RAPD-PCR, which has appeared as a monomorphic band after one week. The same band shows intensity differences among the samples in RAPD-PCR after one week. Note that the number of missing bands is very low for AFLP. 


\section{Research Report}

between individuals, sea-oats generated high polymorphism for samples both within and between populations after screening only eight primers (19-mers) (Figure 1c). Similarly, highly polymorphic bands were observed for both pickerel-weed (Figure 1d) and Penstemon (Figure 1e) samples collected from single populations. Pickerel-weed is self-incompatible (15), and sea-oats exhibits outcrossing mediated by wind pollination $(5,8)$. However, Penstemon is an obligate self-pollinated species. The modified AFLP technique generated extensive polymorphism in the three species at the individual level. The species studied included those inhabiting wetland or terrestrial environments as well as plant taxa belonging to dif- ferent families. These findings confirm that this modified AFLP technique can be conveniently used for genetic characterization of plants.

\section{Reproducibility of Amplified Bands}

For all the species tested, highly reproducible banding patterns were generated for both PCR runs conducted over a period of one month (Figure 2a) and different digestion/ligation reactions conducted for the same DNA (Figure 2b). To obtain a measure of reproducibility, we computed the total number of bands generated in each gel and the number of bands missed later from the initial am plification at different time intervals and digestions. The percent reproducibility (a)
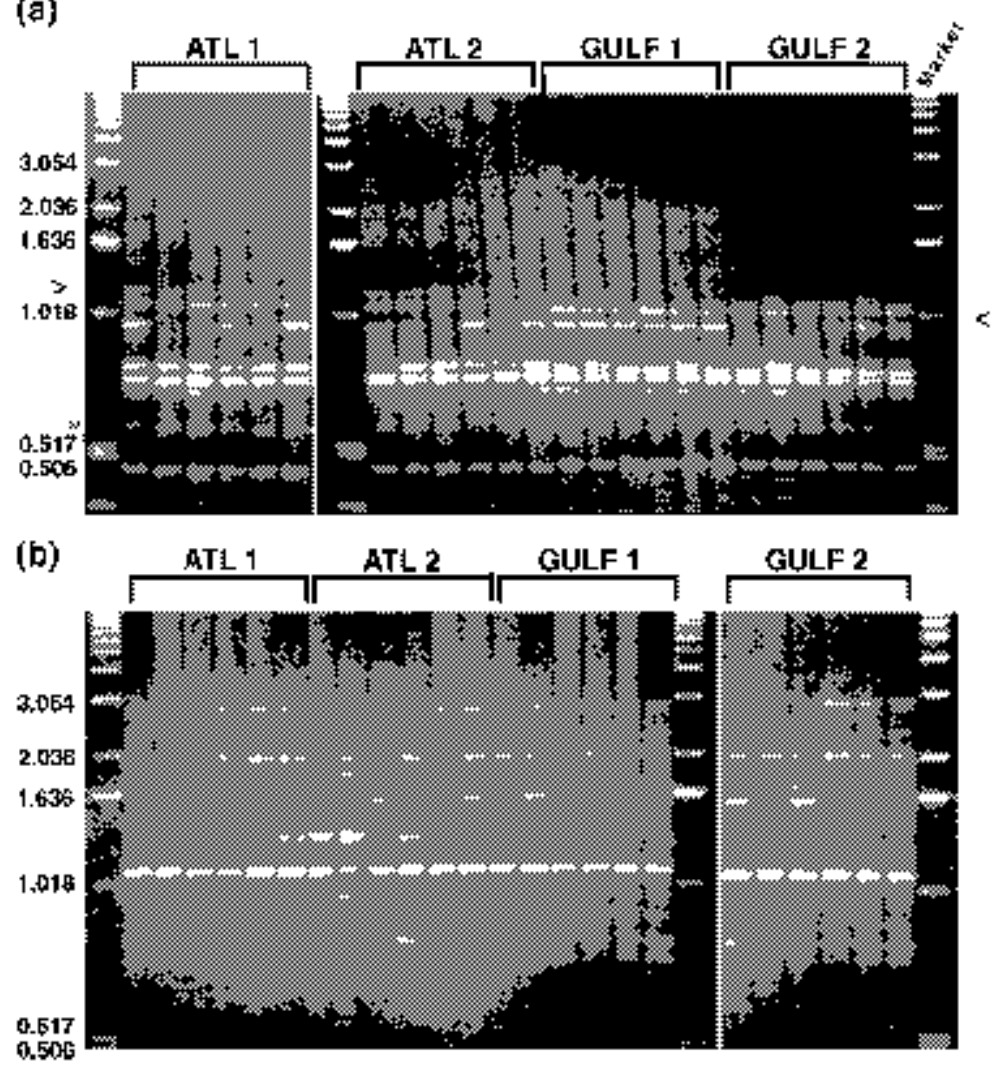

Figure 3. Amplified DNA profiles generated with the modified AFLP and RAPD techniques using samples from four sea-oats ( $U$. paniculata $L$.) populations. Each population consisted of six individual samples. Of the eight primers (19-mer) screened, all generated polymorphism between samples of both within and between populations. (a) DNA profile for primer 5'-GACTGCGTACCAATTCAAT- 3 ' . > indicates polymorphic bands unique to a given coastal origin. (b) RAPD-PCR profiles for random primer OPB8 (Operon Technologies, Alameda, CA, USA). Note the higher number of ambiguous bands present in the RAPD profiles. * indicates separation of bands that differ by 11 bases at the 500-bp range. ATL, Atlantic coast populations; Gulf, Gulf coast populations. of bands was then determined in each case. Between the two digestions and PCR runs, reproducibility was always maintained over $95 \%$.

In comparing modified AFLP with RAPD, we found that the reproducibility of bands using RAPD was highly variable. In some cases, band reproducibility was less than $50 \%$ (Figure 2c). Highly intense bands were largely reproducible. However, some of these bands were completely missing between reactions for the entire samples. Band intensity differences across (or between) the samples were often observed between PCR experiments (Figure 2c). We always observed the formation of a considerable number of faint bands compared to the modified AFLP technique. With RAPD, this led to a high level of ambiguity in scoring the bands for further genetic analysis. In contrast to RAPD, we maintained higher annealing temperatures $\left(56^{\circ} \mathrm{C}\right)$ in the modified AFLP technique that prevented misannealing of primers and production of artifacts. The other reason was the high specificity of the primers that anneal to the adapter sequence sites of the templates in the modified AFLP technique. This high reproducibility is a definite advantage of the modified AFLP over other techniques that use low annealing temperatures and generate amplified bands with the same convenience as the modified AFLP procedure.

\section{RAPD and Modified AFLP Comparison Using Four Sea-Oats Populations}

A comparison between RAPD and modified AFLP was completed to determine their analytical power. Six individuals, each from four sea-oats populations, were used for the study. Eighty random primers were screened to select 10 that would generate polymorphic bands in RAPD. In contrast, only eight AFLP primers (19-mers) were screened, and all generated considerable polymorphism (Figure 3). Ten RAPD primers generated a total of 99 bands of which 49 were polymorphic, while all eight AFLP 19-mers screened generated a total of 95 bands of which 52 were polymorphic. The average number of bands per primer was 9.9 in RAPD and 11.9 in AFLP, while the average number of 
polymorphic bands per primer was 4.9 in RAPD and 6.6 in AFLP. Based on a $t$ test comparison $(\alpha=0.05)$, this modified AFLP generated significantly higher polymorphism per primer than the RAPD procedure. As previously discussed, the bands generated using the modified AFLP technique were more intense than those generated by RAPDs. However, the intensity of RAPD bands could not be improved by adding organic solvents. This characteristic feature of the modified AFLP facilitated the easy scoring of bands (as 0 and 1 data matrices) for statistical data analysis.

RAPD is considered one of the most convenient and low-cost methods to generate genetic markers for identifying different individuals and germ plasm accessions. In addition to the endless source of primers available for thorough multi-loci screening, techniques that use arbitrary primers are less expensive, quick, do not require radioisotopes and can be used to obtain genetic information on genetically unknown organisms $(10,25)$. However, owing to low annealing temperature conditions and nonspecificity of primers, these techniques often generate artifactual bands associated with misannealing of primers and result in poor reproducibility of the markers. Intensity of the bands between individuals can be different, causing ambiguity in scoring bands (10).

In this study, we have demonstrated that the issues of poor band reproducibility, intensity and specificity com monly observed with RAPD could be minimized using the modified AFLP technique while still maintaining significantly higher levels of polymorphism than RAPD, which is usually the main advantage of RAPD. With the modified AFLP technique, two additional steps were necessary compared to other sim ple PCR-based techniques. These were mixing genomic DNA with restriction digestion/ligation mixtures, followed by purification of DNA in preparing the template DNA, which are not complicated steps. However, as observed in this study, time spent on preparing tem plate DNA with the modified AFLP method is negligible compared to the time that can be saved on screening primers for generating polymorphic bands with high reproducibility.

\section{ACKNOWLEDGMENTS}

This article was developed under the auspices of the Florida Sea Grant College Program with support in part from the National Oceanic and Atmospheric Administration, Office of Sea Grant, U.S. Department of Commerce grant no. NA76RG-0120 and the Florida Agricultural Experiment Station. Technical assistance from Alonsua Suazo is acknowledged. This article is Florida Agricultural Experiment Station Journal Series No. R-07217.

\section{REFERENCES}

1.Amos, B, C. Schlotterer and D. Tautz. 1993. Social structure of pilot whales revealed by analytical DNA profiling. Science 260:670672.

2.Avise, J.C. 1994. Molecular Markers, Natural History, and Evolution. Chapman and Hall, New York.

3.Caetano-Anolles, G., B.J. Bassam and P.M. Gresshoff. 1991. DNA amplification fingerprinting using very short arbitrary oligonucleotide primer. BioTechniques 9:553-557.

4.Casey, J. and N. Davidson. 1977. Rates of formation and thermal stabilities of RNA:DNA and DNA:DNA duplexes at high concentrations of formamide. Nucleic Acids Res. 4:1539-1552.

5.Crewz, D.W. 1987. The reproductive response of natural populations of sea oats (Uniola paniculata L., Poaceae) to fertilizer amendment. Final Report. Florida Department of Natural Resources, Division of Marine Resources.

6.Dellaporta, S.L., J. Wood and J.B. Hicks. 1983. A plant DNA minipreparation: version II. Plant Mol. Biol. Rep. 1:19-21.

7.Hadrys, H., M. Balick and B. Schierwater. 1992. Applications of random amplified polymorphic DNA (RAPD) in molecular ecology. Mol. Ecol. 1:55-63.

8.Hester, M.W. and I.A. Mendelssohn. 1987 Seed production and germination response of four Louisiana populations of Uniola paniculata (Gramineae). Am. J. Bot. 74:1093-1101.

9.Janssen, P., R. Coopman, G. Huys, J. Swings, M. Bleeker, P. Vos, M. Zabeau and K. Kersters. 1996. Evaluation of the DNA fingerprinting method AFLP as a new tool in bacterial taxonomy. Microbiology 142:18811893.

10.Karp, A., O. Seberg and M. Buiatti. 1996. Molecular techniques in the assessment of botanical diversity. Ann. Bot. 78:143-149.

11.Li, Q., Q. Cai and C.L. Guy. 1994. A DNA extraction method for RAPD analysis from plants rich in soluble polysaccharides. Plant Mol. Biol. Rep. 12:215-220.

12.Morgante, M. and A.M. Olivieri. 1993. PCR-amplified microsatellites as markers in plant genetics. Plant J. 3:175-182.

13.Mueller, U.G., S.E. Lipari and M.G. Milgroom. 1996. Amplified fragment length polymorphism (AFLP) fingerprinting of sym biotic fungi cultured by the fungus-growing ant Cyphomyrmex minutus. Mol. Ecol. 5:119122.

14.Murray, M.G. and W.F. Thompson. 1980. Rapid isolation of high molecular weight plant DNA. Nucleic Acids Res. 19:4321-4325.

15.Ornduff, R. 1966. The breeding system of Pontederia cordata L. Bull. Torrey Bot. Club 93:407-416.

16.Perlman, D. 1991. A synergistic gelling and sieving agent for gel electrophoresis in normal and low melting temperature agarose. BioTechniques 1 1:754-755.

17.Pomp, D. and J.F. Medrano. 1991. Organic solvents as facilitators of polymerase chain reaction. BioTechniques 10:58-59.

18. Rether, B., G. Delmas and J. Laoued. 1993. Isolation of polysaccharides-free DNA from plants. Plant Mol. Biol. Rep. 11:333-337.

19.Sambrook, J., E.F. Fritsch and T. Maniatis. 1989. Molecular Cloning: A Laboratory Manual. 2nd ed. CSH Laboratory Press, Cold Spring Harbor, NY.

20.Sarkar, G., S. Kapelner and S.S. Sommer. 1990 Formamide can dramatically improve the specificity of PCR. Nucleic Acids Res. 18:7465.

21.Suazo, A. and H.G. Hall. 1999. Modification of the AFLP protocol applied to honey bee (Apis melifera L.) DNA. BioTechniques 26:704-709.

22.Vos, P., R. Hogers, M. Bleeker, M. Reijans, T. Van de Lee, M. Hornes, A. Frijters, J. Pot et al. 1995. AFLP: a new technique for DNA fingerprinting. Nucleic Acids Res. 23:44074414.

23. Weatherhead, P.J. and R.D. Montgomerie. 1991. Good news and bad news about DNA fingerprinting. Trends Ecol. Evol. 6:173-174.

24. Welsh, J. and M. McClelland. 1990. Fingerprinting genomes using PCR with arbitrary primers. Nucleic Acids Res. 18:7213-7218.

25.Williams, J.G.K., A.R. Kubelik, K.J. Livak, J.A. Rafalski and S.V. Tingey. 1990. DNA polymorphisms amplified by arbitrary primers are useful as genetic markers, Nucleic Acids Res. 8:6531-6535.

26. Winship, P.R. 1989. An improved method for directly sequencing PCR amplified material using dimethyl sulfoxide. Nucleic Acids Res. 17:1266.

27.Zhang, W., G. Hu and A. Deisseroth. 1991. Improvement of PCR sequencing by formamide. Nucleic Acids Res. 19:6649.

Received 15 November 1999; accepted 28 June 2000.

\section{Address correspondence to:}

Dr. Michael E. Kane

Department of Environmental Horticulture

PO Box 110670

University of Florida

Gainesville, FL, USA

e-mail:mek@gnv.ifas.ufl.edu 